\title{
Evaluation of Moving Average Window Technique as Low-pass Filter in Microprocessor-Based Protecting Relays
}

\author{
Naser Khodabakhshi-Javinani \\ Electrical Engineering Department \\ Amirkabir University of Technology \\ Tehran, Iran \\ naser@aut.ac.ir
}

\author{
Hossein Askarian-Abyaneh \\ Electrical Engineering Department \\ Amirkabir University of Technology \\ Tehran, Iran \\ askarian@aut.ac.ir
}

\begin{abstract}
Over the last decades, with the increase in the use of harmonic source devices, the filtering process has received more attention than ever before. Digital relays operate according to accurate thresholds and precise setting values. In signal flow graphs of relays, the low-pass filter plays a crucial role in prefiltering and purifying waveforms performance estimating techniques to estimate the expected impedances, currents, voltage etc. The main process is conducted in the CPU through methods such as Man and Morrison, Fourier, Walsh-based techniques, least-square methods etc. To purify waveforms polluted with loworder harmonics, it is necessary to design and embed cutting frequency in a narrow band which would be costly. In this article, a technique is presented which is able to eliminate specified harmonics, noise and DC offset, attenuate whole harmonic order and hand low-pass filtered signals to CPU. The proposed method is evaluated by eight case studies and compared with first and second order low-pass filter.
\end{abstract}

Keywords-Low-pass Filter; Power System Protection; Harmonics and noisy waveforms; Moving Average Window (MAW); Central Processing Unit (CPU)

\section{INTRODUCTION}

Disturbances are a main power quality issue in power systems. Voltage and current waveform distortions such as harmonics and noises are the main disturbances. Distorted waveform might be originated by sources, appliances, and loads [1-4]. Most of the harmonic sources such as power electronic converters, inject different levels of harmonics to the power grid. The harmonic sources can be divided into the following categories in a power grid [5-7]:

- Electrical machines (in point of physically distortion creation) and non-linear loads are defined as nonsemiconductor based harmonic sources.

- Motor control devices, HVDC power transmission system, FACTS systems, electrical vehicle and cyclo-converters in low-speed and high torque machines are called semiconductor based harmonic sources.

As introduced in [8], Adjustable Speed Driver (ASD), capacitors, circuit breakers, fuses, conductors, lighting, meters, transformers, rotating machines, telephone interference and protective relaying are affected by harmonics distortion. International standards for power quality such as IEEE519, IEC 61000, and EN 50160 established admissible harmonic levels and their emission limits [9-11]. A prior research on power system harmonics has been done in 1983 by an IEEE working group [12]. Along with 50 years of operational reports, the effect of harmonics has been categorized in some clauses. The 8th clause of this report points to relay malfunction by harmonics [5]. This topic is notable when the decision-making process depends on the rate of waveform distortion. This distortion affects the operating point of relays and consequently the decision-making system [13]. In protective relays, most of the measurement units determine the peak value and the zero crossing of the voltage and current waveforms. Therefore, the harmonics can cause mis-operation of the microprocessorbased relays [14]. This issue has notably been investigated in case of power distribution system protection conducted on static under-frequency and over-current relays [15]. Authors in $[7,16]$ presented analytical approaches based on relay characteristics and performed theoretical and experimental analysis to derive phase angles of low-order harmonics on the tripping time of overcurrent relays. Harmonic order and amplitudes are determinant. Authors in [17] indicated the effects of noisy electrical signals on digital relays and they proposed a filter capable of filtering selective harmonic components. A low-pass filter is a well known yet primitive approach to deal with power system harmonics. To eliminate low-order harmonics, low-pass filter with sharp cut-off frequency is required and that frequency should be set among the fundamental and the next order harmonics [1]. Setting the cut-off frequency in a narrow frequency band makes the design complex. Although the process of low-pass filter design is theoretically effortless, it is practically not economical in order to filter low order harmonics.

Any distortion may lead to unexpected relay operation. This fact is apparent especially in overcurrent relays [17, 19]. The fast operation of the relays is influenced by harmonic current which is less or more than nominal $[20,21]$. This deviation is limited to $15 \%$. In over current relays and with the presence of low-order harmonics, they can operate up to $60 \%$ faster than 
normal and standard condition [22]. Harmonics also have undeniable effects on frequency protection relays. In under frequency relays, the $10 \% \mathrm{THD}$, increases operating time twice. Therefore, it is recommended to limit the harmonic pollution to $5 \%$ [23]. Also, harmonics have a severe impact on differential relays. Figure 1shows the basic components of the typical digital relay which LP filter situates after surge protective circuits Although the prevalent low-pass filtering might be suitable for high-frequency harmonics, the performance and cost are considerable especially in filtering low-order harmonics [24]. There are many detection and calculation algorithms and techniques operated on filtereddiscrete waveforms to estimate operation territory such: Mann \& Morrison method [25], Rockefeller \& Udren technique [26], Fourier and Walsh-based technique [27, 28], least-square methods [29], differential equation technique and travellingwave-based methods but they are applied in Central Processing Units (CPU) [30].
The Moving Average Window (MAW) technique is a numeric-mathematical based transform function to simulate the waveform with selective resolution. Also, the averaging technique used to model discrete spaces to continuous one such as switches in converters [18]. In low pass filter design, setting sharp cutting frequency makes the design process complex and costly. The proposed method is an efficient technique to estimate signals with variable resolution. In this article, the MAW technique in two schemes is compared with the common first and second order low-pass filters which are applied in protective relays. Figure 1 describes MAW embedded in the protective relay as a low-pass filter. The MAW has the sampling frequency as the only tuning parameter and its response is comparable with the second order filter design with two tuning parameters. The design simplicity and the low computational burden is the two main advantages of the proposed method.

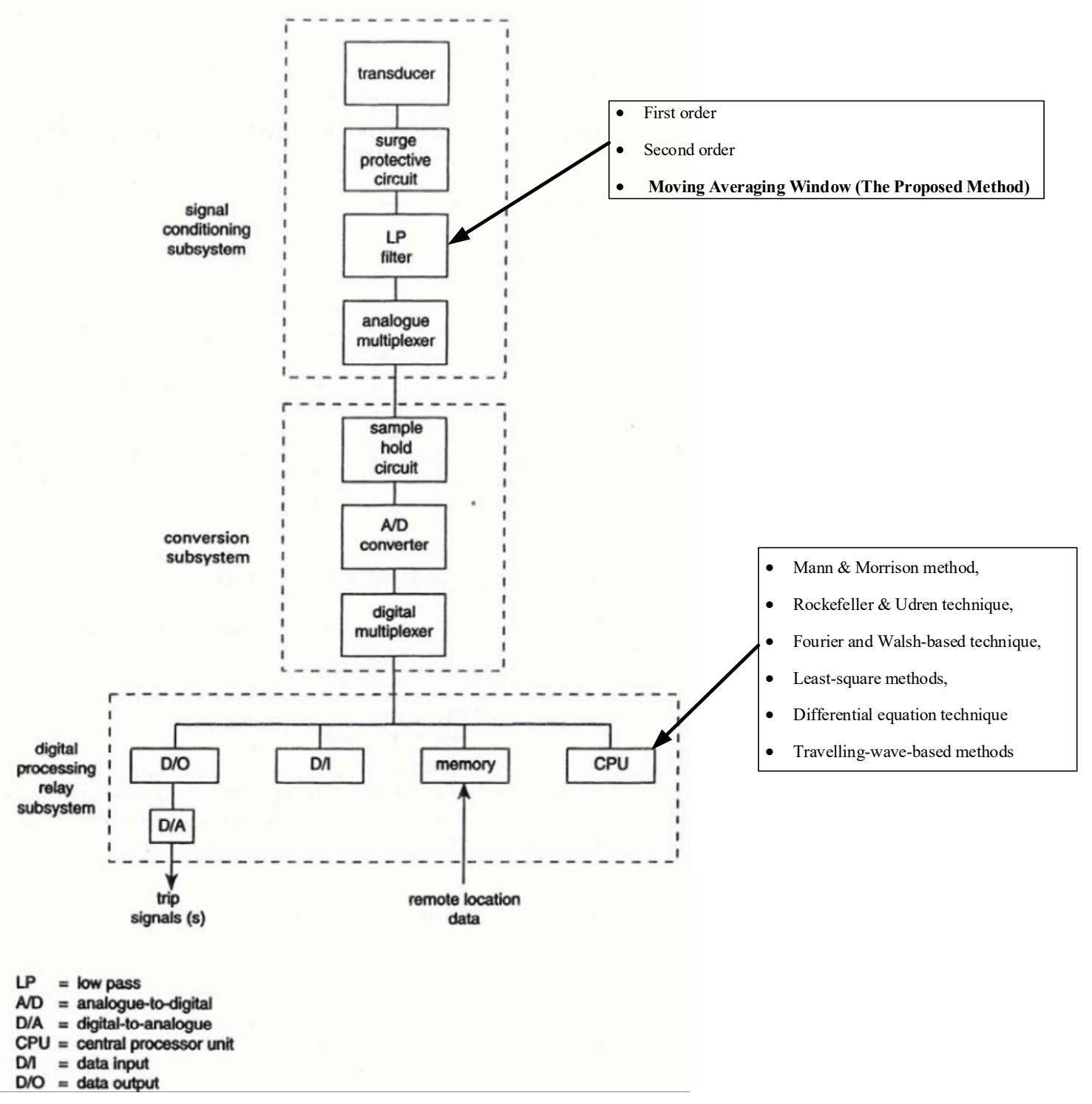

Fig. 1. Basic components of a digital relay and the situation of Moving Averaging Window in filtering process. 


\section{PROPOSED METHOD}

In order to design a conventional low-pass filter, the optimal tuning of a sharp and accurate cutoff frequency is required, something complicated and cost-effective in implementation. The Moving Averaged Window (MAW) technique can estimate the fundamental only through selecting a proper sampling frequency.

\section{A. Moving Average Window}

Many studies have been published on MAW applications in signal processing and modeling scope. MAW applications are summarized in the estimation of waveforms with various degree of resolution and rate of processing power [18]. The MAW technique is capable of fault detection, direction estimation, and faulty phase identification [31-33]. This technique is less sensitive to noise for sampling frequency around the noise frequency. The proposed technique defines a transfer function in continuous time-domain mode. Equation (1) shows MAW transfer function wherein $\mathrm{x}(\mathrm{t})$ is under process waveform. $\bar{x}(t)$ is averaged waveform along window length of $\mathrm{T}_{\mathrm{S}}$.

$$
\bar{x}(t)=\frac{1}{T_{S}} \int_{t-T_{S}}^{t} x(\tau) d \tau
$$

The frequency response of (1) is shown in (2) which is the Fourier transform of impulse response of (1) and is called lowpass filter frequently [31].

$$
\bar{X}(j \omega)=e^{-j \frac{\omega T_{S}}{2}} \operatorname{sinc}\left(\frac{\omega T_{S}}{2}\right)
$$

where $\operatorname{sinc}(\alpha)=\sin (\alpha) / \alpha, \mathrm{T}_{\mathrm{s}}$, and $\mathrm{f}_{\mathrm{s}}$ are sampling time and frequency respectively and $\mathrm{f}_{\mathrm{s}}$ defines the sampling/window length. The moving window is demonstrated in Figure 2. Figure 3 shows the MAW's frequency response. In Figure 3(a), $\omega$ frequency (nominal frequency) is rejected by the filter in $\pi$ radian phase and other frequencies are attenuated except dc. Selecting TS, the filter output can be zero at fS. As shown in Figure 3(b), the filter's phase response lags. The shown characteristic in amplitude and phase could lead up to article's main purpose of the usage of MAW as a low-pass filter.

\section{B. Filter Response to Harmonic Polluted Signal}

By applying polluted waveform in (1) as the input variable, (3) is obtained, which shows mathematical-time domain of harmonically distorted signals with odd-order frequencies.

$$
x(t)=x_{0}+\sum_{k=1}^{n} x_{2 k+1} \sin \left(2 \pi f_{2 k+1} t+\varphi_{2 k+1}\right)
$$

where, $\mathrm{x}_{1}$ is the fundamental frequency, $\mathrm{x}_{2 \mathrm{k}+1}$ and $\mathrm{f}_{2 \mathrm{k}+1}$ are oddharmonic order amplitude and frequencies, respectively and $\varphi_{2 k+1}$ is corresponded phase angle. Applying (1) to (3), the averaged equation is derived as

$\bar{x}(t)=x_{0}+\sum_{k=1}^{n} \bar{a}_{2 k+1} \sin \left(2 \pi f_{2 k+1} t+\varphi_{2 k+1}-\pi f_{2 k+1} T_{S}\right)$

$$
\bar{a}_{2 k+1}=x_{2 k+1} \operatorname{sinc}\left(\pi f_{2 k+1} T_{S}\right)
$$

where $\pi f_{2 k+1} T_{s}$ is phase lagging in filtered signal. In Figure 4, the amplitudes of 13 harmonic orders are illustrated by different averaging window frequencies. In Figure 4 we see that the amplitude of harmonics varies by sampling frequency. The main idea lies there. Since high sampling frequency leads to the amplifying of harmonics order, in some frequencies, harmonic orders tend to be zero. The zero crossing frequencies are an integer multiple of each harmonic frequency. Table I shows the amplitude of each zero-crossing frequency which plays an important role in MAW philosophy.

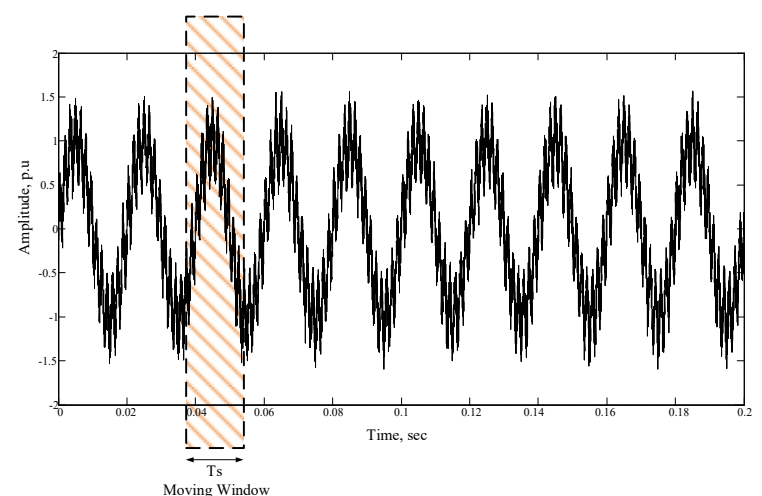

Fig. 2. Moving Window applied to distorted input waveform containing harmonics and Gaussian noise with variance 0.01
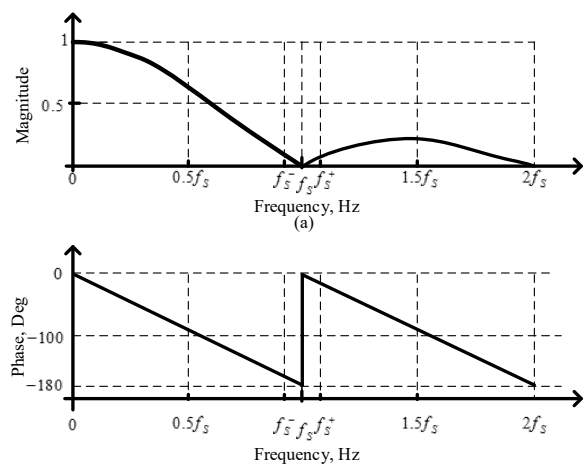

(b)

Fig. 3. The proposed filter characteristics based on MAW. (a) Magnitude response. (b) Phase response

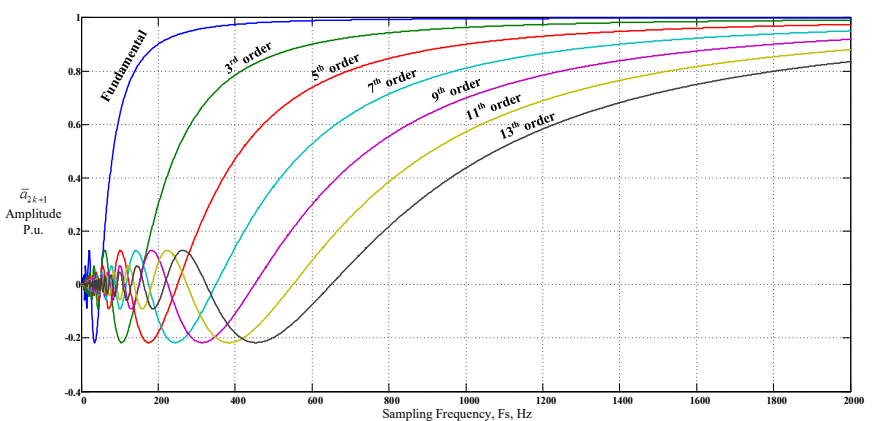

Fig. 4. The amplitude of response of MAW by varying sampling frequency up to 13th harmonic order 
In fact, averaging theory waived harmonic order which is swept with the corresponding frequency. In Table I, by selecting $150 \mathrm{~Hz}$ as MAW sampling frequency, weakening the related harmonic order (3rd and 9th) is achieved. This fact is carried out on other harmonic orders. Table II shows the phase lagging of each selected sample frequency. As it can be derived from Tables I and II, by applying $\mathrm{f}_{\mathrm{s}}=150 \mathrm{~Hz}, 300$-degree phase lagging in fundamental and $17.32 \%$ decaying in magnitude are achieved. In section IV, two filtering strategies are discussed and the ability of MAW would be evaluated in comparison with first and second order low-pass filter.

TABLE I. THE AMPLITUDE OF HARMONIC ORDER IN ZERO-CROSSING FREQUENCY

\begin{tabular}{|c|c|c|c|c|c|c|c|}
\hline & \multicolumn{7}{|c|}{ Harmonic Order } \\
\hline $\mathbf{f s}(\mathbf{H z})$ & $\mathbf{1}^{\text {st }}$ & $\mathbf{3}^{\text {rd }}$ & $\mathbf{5}^{\text {th }}$ & $\mathbf{7}^{\text {th }}$ & $\mathbf{9}^{\text {th }}$ & $\mathbf{1 1}^{\text {th }}$ & $\mathbf{1 3}^{\text {th }}$ \\
\hline $\mathbf{1 5 0}$ & 0.827 & 0 & 0.1654 & 0.1181 & 0 & 0.0752 & 0.0636 \\
\hline $\mathbf{2 5 0}$ & 0.9355 & 0.5045 & 0 & 0.2162 & 0.1039 & 0.085 & 0.1164 \\
\hline $\mathbf{3 5 0}$ & 0.9667 & 0.7241 & 0.3484 & 0 & 0.1935 & 0.1974 & 0.0744 \\
\hline $\mathbf{4 5 0}$ & 0.9798 & 0.827 & 0.5642 & 0.263 & 0 & 0.1674 & 0.217 \\
\hline $\mathbf{5 5 0}$ & 0.9864 & 0.882 & 0.6931 & 0.455 & 0.2103 & 0 & 0.1456 \\
\hline 650 & 0.9903 & 0.9146 & 0.7738 & 0.5868 & 0.3784 & 0.1748 & 0 \\
\hline
\end{tabular}

TABLE II. PHASE LAGGING DEGREE IN APPLYING MAW WITH VARIABLE SAMPLING FREQUENCY

\begin{tabular}{|c|c|c|c|c|c|c|c|}
\hline & \multicolumn{7}{|c|}{ Harmonic Order } \\
\hline $\mathbf{f s} \mathbf{( H z )}$ & $\mathbf{1}^{\text {st }}$ & $\mathbf{3}^{\text {rd }}$ & $\mathbf{5}^{\text {th }}$ & $\mathbf{7}^{\text {th }}$ & $\mathbf{9}^{\text {th }}$ & $\mathbf{1 1}^{\text {th }}$ & $\mathbf{1 3}^{\text {th }}$ \\
\hline $\mathbf{1 5 0}$ & 300 & 180 & 60 & 300 & 180 & 60 & 300 \\
\hline $\mathbf{2 5 0}$ & 324 & 252 & 180 & 108 & 36 & 324 & 252 \\
\hline $\mathbf{3 5 0}$ & 334.28 & 282.85 & 231.43 & 180 & 128.57 & 77.14 & 25.71 \\
\hline $\mathbf{4 5 0}$ & 340 & 300 & 260 & 220 & 180 & 140 & 100 \\
\hline $\mathbf{5 5 0}$ & 343.64 & 310.91 & 278.18 & 245.45 & 212.73 & 180 & 147.27 \\
\hline $\mathbf{6 5 0}$ & 346.15 & 318.46 & 290.77 & 263.07 & 235.38 & 207.69 & 180 \\
\hline
\end{tabular}

\section{SimUlation AND RESUlt}

\section{A. DC Offset Elimination}

According to Figure 3 and to the frequency response of MAW, the DC component is amplified to $100 \%$. The MAW technique is capable of eliminating DC offset of input waveforms easily through surviving MAW in fundamental frequency. Figure 5 shows the process of DC offset elimination which is proposed by MAW with a fundamental frequency sweep, e.g. fs $=50 \mathrm{~Hz}$, DC offset totally removed.

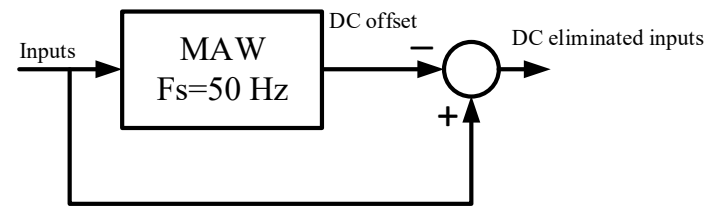

Fig. 5. Proposed method for eliminating of DC offset on input waveforms before the main filtering

\section{B. Sampling Frequency, $f_{s}$}

Sampling frequency has a crucial role in estimating fundamental waveform and harmonic's content. The sampling frequency is obtained by inherent characteristics of local harmonic properties. In order to filter the harmonic polluted waveforms, two harmonic elimination strategies are defined. Figure 6 shows the flowchart in explanation of these strategies. As it shows, the $f_{s}$ has a key role in this filtering process.

\section{1) Selective Harmonic Elimination}

Due to selective harmonic order elimination, it is enough to select corresponding harmonic frequency as the sampling frequency. Table I illustrates selective harmonic scheme.

\section{2) General Harmonic Attenuation}

As it can be derived from Table I, by selecting $\mathrm{f}_{\mathrm{s}}=150 \mathrm{~Hz}$, the harmonic reduction is started with the aim of maximum elimination of $3^{\text {rd }}$ harmonic order. This strategy is defined as selective harmonic weakening by concentration on $3^{\text {rd }}$ harmonic order elimination. In General Harmonic Attenuation strategy, the objective function sets on achieving minimum THD. In this strategy, $f_{s}$ tunes to minimize output THD by applying MAW.

\section{3) MAW Technique Evaluation}

In order to prove MAW sufficiency, the simulation is performed by comparing two conventional low-pass filters and MAW. Table III shows 8 case studies of polluted waveforms. The first two cases of Table III present the most common harmonic existence with notable amplitude in the power system. The THD would be considered as a criterion pollution rate $[32,33]$.

The simulation was performed on first order low-pass filter (LPF-1), second order low-pass filter (LPF-2), MAW-General, and MAW-Selective. Table IV presents the result of filtered case studies which have been introduced in Table III. The first two columns are the result of the first and second order traditional low-pass filter. These filter characteristics are given in Appendix. The last two columns result applied general and selective MAW to these case studies. Methodologies have been discussed in section IV. According to first order filtering results in case 1 , the THD decreases from $60.21 \%$ to $23.99 \%$ and fundamental weakens from $100 \%$ to $71 \%$. The second order low-pass filter is set on high-quality factors and the full amount of fundamental amplitude. Two parameters $\left(\omega_{c}, \xi\right)$ should be set and therefore, two poles add to system transfer function order level. The result shows that by applying second order $\mathrm{LPF}$, fundamental is kept to $100 \%$ and THD factor decreased to $5.98 \%$. Filtering with MAW-General strategy has been done by setting $\mathrm{f}_{\mathrm{s}}=144 \mathrm{~Hz}$ to achieve minimum THD. In the case of presence of various harmonic orders, the general MAW suggested for general decreasing harmonic content. In addition, Table IV shows the ability of MAW technique in both general and selective harmonic decaying. The result is that MAW has the best performance in comparison to traditional low-pass filtering methods. As for the various order of harmonics, the MAW-General scheme results better than MAW -Selective. Similarly, in the polluted waveform with specific harmonic order, the MAW-Selective has the best performance. Figure 7 illustrates the effect of LPF1, LPF2, MAW-General and MAW-Selective on case 1. FFT analysis is calculated with transient-free waveforms through THD, TIHD and TSHD. 


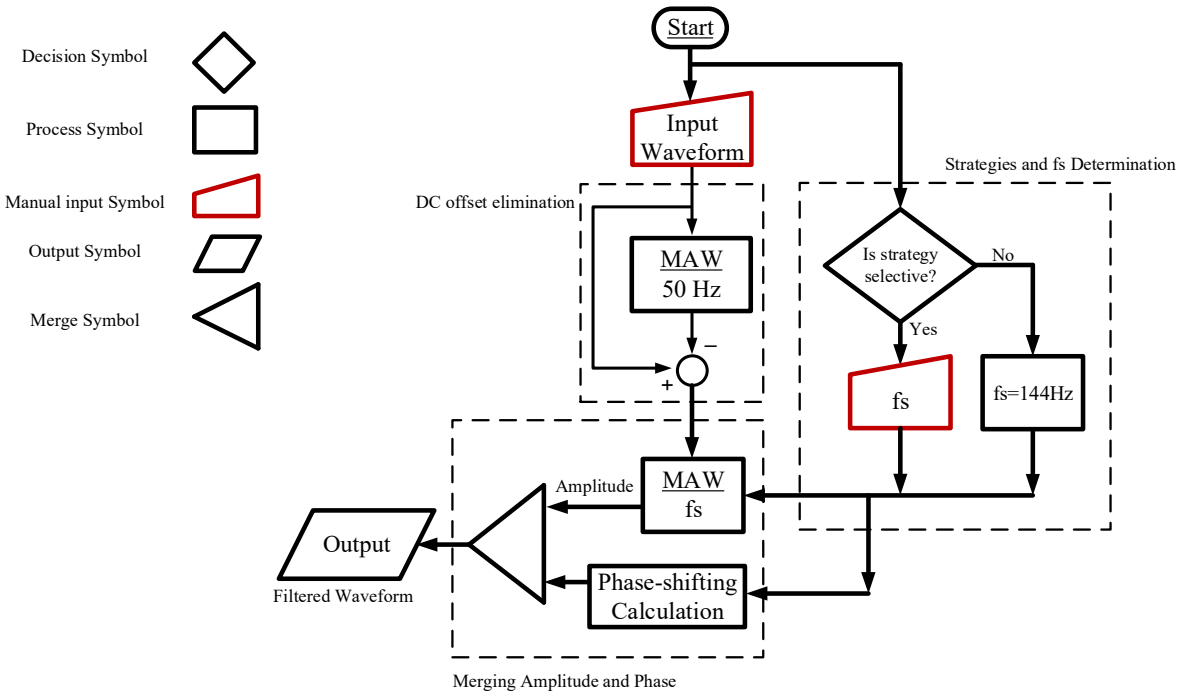

Fig. 6. Proposed technique flowchart

TABLE III. 8 CASE STUDIES EVALUATING BY MAY TECHNIQUE

\begin{tabular}{|c|c|c|c|c|c|c|c|c|c|}
\cline { 2 - 10 } \multicolumn{2}{c|}{} & Fundamental & $\mathbf{3}^{\text {rd }}$ & $\mathbf{5}^{\text {th }}$ & $\mathbf{7}^{\text {th }}$ & $\mathbf{9}^{\text {th }}$ & $\mathbf{1 1}^{\text {th }}$ & $\mathbf{1 3}^{\text {th }}$ & THD \\
\hline \multirow{4}{*}{} & $\mathbf{1}$ & $100 \%$ & $50 \%$ & $30 \%$ & $10 \%$ & $8 \%$ & $6 \%$ & $5 \%$ & $60.21 \%$ \\
\cline { 2 - 10 } & $\mathbf{2}$ & $100 \%$ & $50 \%$ & $50 \%$ & $10 \%$ & 0 & 0 & 0 & $71.41 \%$ \\
\cline { 2 - 10 } & $\mathbf{3}$ & $100 \%$ & $50 \%$ & 0 & 0 & 0 & 0 & 0 & $50 \%$ \\
\cline { 2 - 10 } & $\mathbf{4}$ & $100 \%$ & 0 & $30 \%$ & 0 & 0 & 0 & 0 & $30 \%$ \\
\cline { 2 - 10 } & $\mathbf{5}$ & $100 \%$ & 0 & 0 & $30 \%$ & 0 & 0 & 0 & $30 \%$ \\
\cline { 2 - 10 } & $\mathbf{6}$ & $100 \%$ & 0 & 0 & 0 & $30 \%$ & 0 & 0 & $30 \%$ \\
\cline { 2 - 10 } & $\mathbf{7}$ & $100 \%$ & 0 & 0 & 0 & 0 & $30 \%$ & 0 & $30 \%$ \\
\cline { 2 - 10 } & $\mathbf{8}$ & $100 \%$ & 0 & 0 & 0 & 0 & 0 & $30 \%$ & $30 \%$ \\
\hline
\end{tabular}

\section{CONCLUSION}

The signal processing of digital relays has mainly focused on algorithms to find out and estimate the operation criteria. Many techniques and methods have been proposed. It is clear that pre-filtering produces better results when using a low-pass filter. The design of sharp cutting frequency among fundamental and first harmonic order, causes complexity and cost. Therefore the Moving Average Window was proposed to eliminate DC offset, noise and attenuate harmonic content. The proposed technique could satisfyingly substitute the traditional first and second order low-pass filter. The evaluation test was done in 8 case studies and the results are tabulated and illustrated. The MAW has the ability to eliminate specified harmonic order or attenuate whole harmonic order. Thus, two filtering strategies are defined and verified with the 8 case studies. Low computational burden and only one tuning parameter $\left(f_{s}\right)$ are two main advantages of MAW.

TABLE IV. RESUlt OF 8 CASE STUDIES FILTERING BY 4 STRATEGIES: LPF-1, LPF-2, MAW-GENERAL AND MAW SELECTIVE

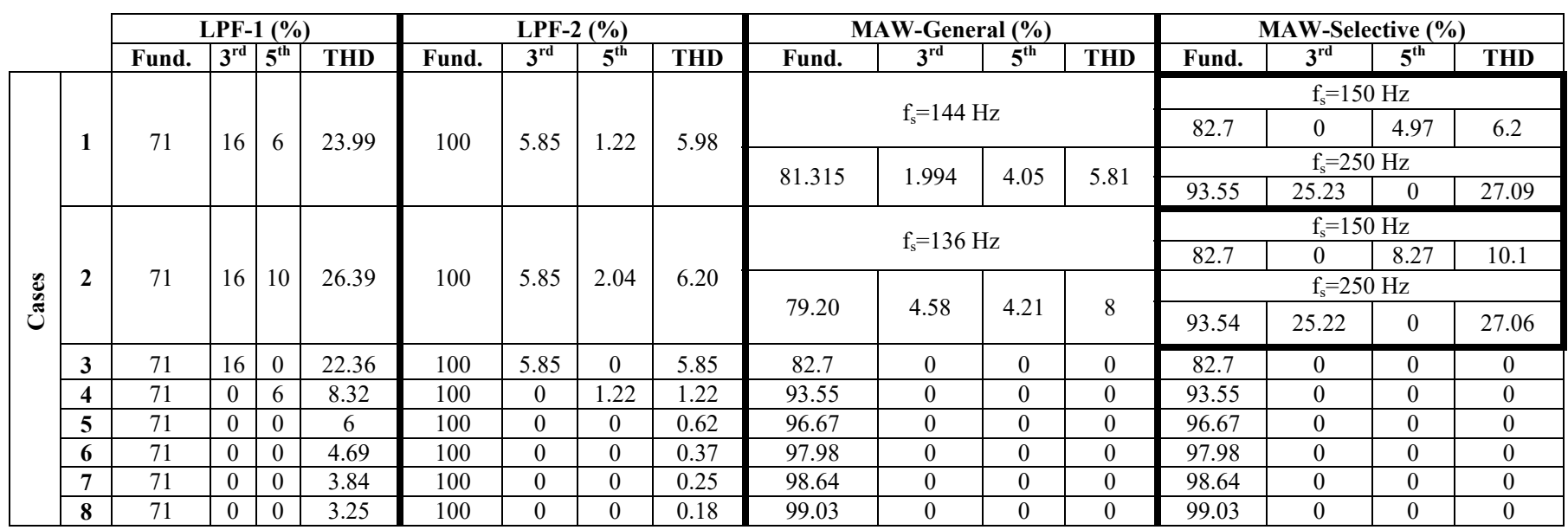



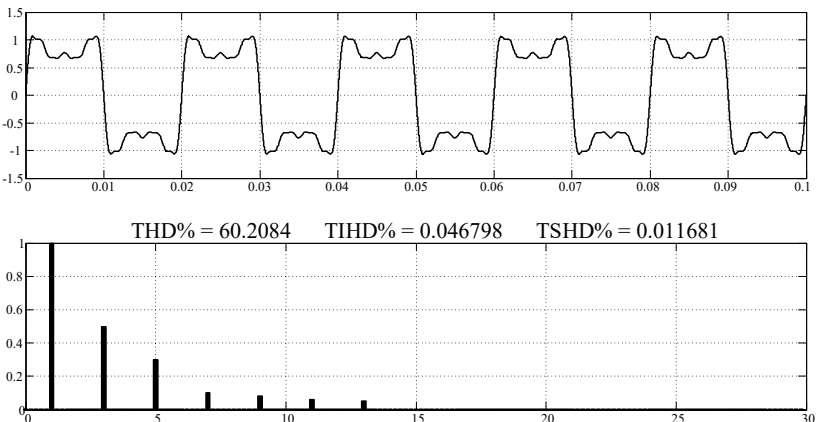

$\mathrm{a}$
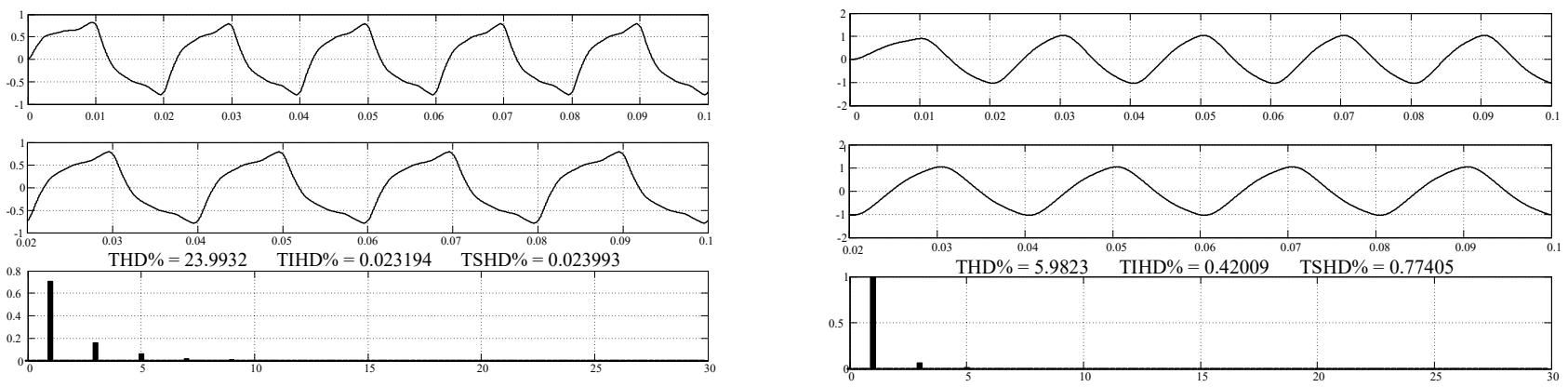

b
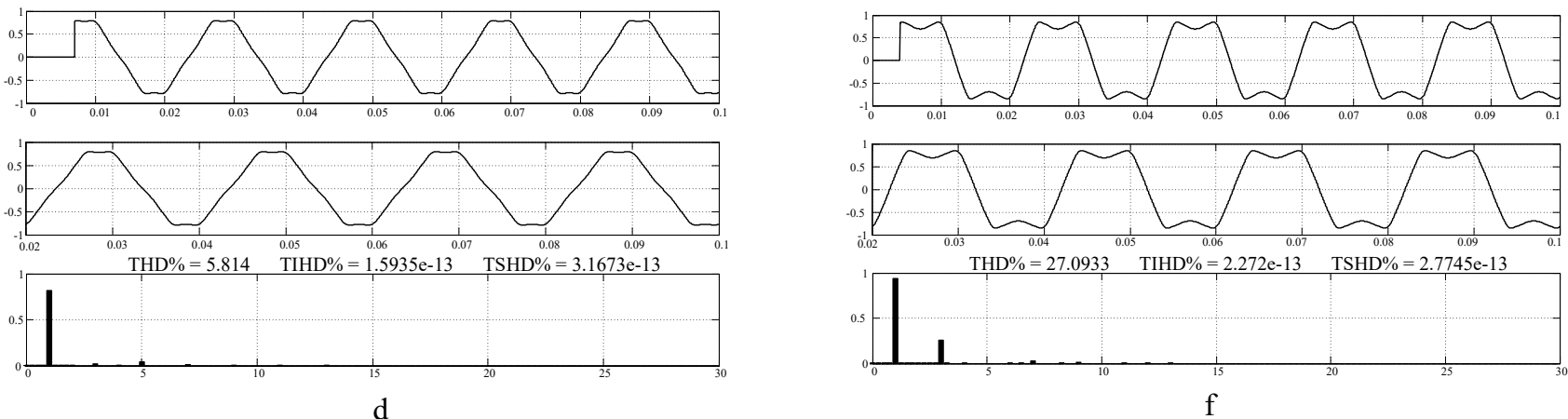

Fig. 7. Simulation result of case 1: (a) Original waveform (b) LPF1 waveform both original and without transient-free waveform (c) LPF2 waveform both original and transient-free waveform (d) MAW-General with Fs=144 Hz both original and transient-free waveform (e) MAW-Selective with Fs=150 $\mathrm{Hz}$ both original and transient-free waveform (f) MAW-Selective with $\mathrm{Fs}=250 \mathrm{~Hz}$ both original and transient-free wavefor

\section{APPENDIX}

\section{FIRST ORDER LOW-PASS FILTER}

$$
H(s)=\frac{1}{1+\frac{s}{\omega_{c}}}
$$

Where, $\omega_{c}=2 \pi f_{c}$ and $f_{c}$ is the cutting frequency which is set on $50 \mathrm{~Hz}$ for achieving maximum THD

\section{SECOND ORDER LOW-PASS FILTER}

$$
H(s)=\frac{1}{1+\frac{2 \xi}{\omega_{c}} s+\frac{s^{2}}{\omega_{c}{ }^{2}}}
$$

Where $\omega_{\mathrm{c}}=2 \pi \mathrm{f}_{\mathrm{c}}$ and $\mathrm{f}_{\mathrm{c}}$ is the cutting frequency which is set on $50 \mathrm{~Hz}$. $\xi$ is damping ration which is set on 0.5 for achieving better quality factor.

\section{REFERENCES}

[1] W. Rebizant, J. Szafran, A. Wiszniewski, Digital signal processing in power system protection and control, Springer Science \& Business Media, 2011

[2] M. H. J. Bollen, I. Y. H. Gu, Signal processing of power quality disturbances, John Wiley \& Sons, 2006

[3] S. Upadhyaya, S. Mohanty, C. N. Bhende, "Hybrid Methods for Fast Detection and Characterization of Power Quality Disturbances", Journal of Control, Automation and Electrical Systems, Vol. 26, No. 5, pp. 556566, 2015

[4] S. Khokhar, A. A. B. Mohd Zin, A. S. B. Mokhtar, M. Pesaran, "A comprehensive overview on signal processing and artificial intelligence techniques applications in classification of power quality disturbances", Renewable and Sustainable Energy Reviews, Vol. 51, pp. 1650-1663, 2015

[5] R. Yacamini, "Power system harmonics. Part 1. Harmonic sources", Power Engineering Journal, Vol. 8, No. 4, pp. 193-198, 1994

[6] J. Arrillaga, N. R. Watson, "Harmonic Sources", in Power System Harmonics, John Wiley \& Sons, pp. 61-142, 2004

[7] M. A. S. Masoum, A. S. Masoum, A. S. Masoum, "Influence of low order harmonic phase angles on tripping time of overcurrent relays", 
40th North American Power Symposium, pp. 1-5, Calgary, Canada, 2008

[8] V. E. Wagner, J. C. Balda, D. C. Griffith, A. McEachern, T. M. Barnes, D. P. Hartmann, D. J. Phileggi, A. E. Emannuel, W. F. Horton, W. E. Reid, R. J. Ferraro, W.T. Jewell, "Effects of harmonics on equipment", IEEE Transactions on Power Delivery, Vol. 8, No. 2, pp. 672-680, 1993

[9] IEEE Recommended Practice and Requirements for Harmonic Control in Electric Power Systems, IEEE Std 519-2014 (Revision of IEEE Std 519-1992), pp. 1-29, 2014

[10] I. E. C., Electromagnetic compatibility (EMC), 2014

[11] H. Markiewicz, A. Klajn, Voltage characteristics of electricity supplied by public distribution networks, Copper Development Assosiation, 2004

[12] Power Harmonics, "Power System Harmonics: An Overview", IEEE Transactions on Power Apparatus and Systems, Vol. PAS-102, No. 8, pp. 2455-2460, 1983

[13] W. F. Horton S. Goldberg, "The Effect of Harmonics on the Operating Points of Electromechanical Relays", IEEE Power Engineering Review, Vol. PER-5, No. 5, pp. 45-46, 1985

[14] M. Shao, P. Poonpun, W. T. Jewell, "An advanced methodology for under-frequency load shedding relay testing", Transmission and Distribution Conference and Exposition, pp. 1-4, Chicago, USA, 2008

[15] J. F. Fuller, E. F. Fuchs, D. J. Roesler, "Influence of harmonics on power distribution system protection", IEEE Transactions on Power Delivery, Vol. 3, No. 2, pp. 549-557, 1988

[16] M. A. S. Masoum, S. M. Islam, K. Tan, N. X. Tung, "Impact of harmonics on tripping time of overcurrent relays", 2007 Australasian Universities Power Engineering Conference, pp. 1-5, 2007

[17] J. Lazaro, J. F. Minambres, M. A. Zorrozua, "Selective estimation of harmonic components in noisy electrical signals for protective relaying purposes", International Journal of Electrical Power \& Energy Systems, Vol. 56, pp. 140-146, 2014

[18] R. W. Erickson, D. Maksimovic, Fundamentals of Power Electronics: Springer, 2001

[19] V. Gurevich, Cyber and Electromagnetic Threats in Modern Relay Protection, Crc Press, 2014

[20] J. M. Ho, C. C. Liu, "The effects of harmonics on differential relay for a transformer", 16th International Conference and Exhibition on Electricity Distribution, Part 1: Contributions. CIRED, Vol. 2, pp. 5, 2001

[21] M. Kezunovic, B. Kasztenny, "Design optimization and performance evaluation of the relaying algorithms, relays and protective systems using advanced testing tools", 21st IEEE International Conference on Power Industry Computer Applications, pp. 309-314, 1999

[22] P. M. Donohue, S. Islam, "The Effect of Nonsinusoidal Current Waveforms on Electromechanical and Solid-State Overcurrent Relay Operation", IEEE Transactions on Industry Applications, Vol. 46, No. 6, pp. $2127-2133,2010$

[23] E. F. Fuchs, D. J. Roesler, M. A. S. Masoum, "Are harmonic recommendations according to IEEE and IEC too restrictive?", IEEE Transactions on Power Delivery, Vol. 19, No. 4, pp. 1775-1786, 2004

[24] A. T. Johns, S. K. Salman, Digital protection for power systems: IET, 1997

[25] B. J. Mann, I. Morrison, "Digital calculation of impedance for transmission line protection", IEEE Transactions on Power Apparatus and Systems, Vol. PAS-90, No. 1, pp. 270-279, 1971

[26] G. Rockefeller, "Fault protection with a digital computer", IEEE Transactions on Power Apparatus and Systems, Vol. PAS-88, No. 4, pp. 438-464, 1969

[27] A. Johns, M. Martin, "Fundamental digital approach to the distance protection of EHV transmission lines", Proceedings of the Institution of Electrical Engineers, Vol. 125, No. 5, pp. 377-384, 1978

[28] J. W. Horton, "Use of Walsh functions for high-speed digital relaying", IEEE PES Summer Meeting, San Francisco, Paper No.A75-582-7, pp.19. 1975

[29] A. Ranjbar, B. Cory, "An improved method for the digital protection of high Voltage transmission lines", IEEE Transactions on Power Apparatus and Systems, , Vol. 94, No. 2, pp. 544-550, 1975
[30] Q.-H. Wu, Z. Lu, T. Ji, Protective relaying of power systems using mathematical morphology, Springer Science \& Business Media, 2009

[31] S. Dambhare, S. A. Soman, M. C. Chandorkar, "Current Differential Protection of Transmission Line Using the Moving Window Averaging Technique", IEEE Transactions on Power Delivery, Vol. 25, No. 2, pp. 610-620, 2010

[32] S. M. Hashemi, M. Tarafdar Hagh, H. Seyedi, "Transmission-Line Protection: A Directional Comparison Scheme Using the Average of Superimposed Components", IEEE Transactions on Power Delivery, Vol. 28, No. 2, pp. 955-964, 2013

[33] A. K. Pradhan, A. Routray, S. R. Mohanty, “A Moving Sum Approach for Fault Detection of Power Systems", Electric Power Components and Systems, Vol. 34, No. 4, pp. 385-399, 2006 